Felix Creutzig, Aneeque Javaid, Zakia Soomauroo, Steffen Lohrey, Nikola Milojevic-Dupont, Anjali Ramakrishnan, Mahendra Sethi, Lijing Liu, Leila Niamir, Christopher Bren d'Amour, Ulf Weddige, Dominic Lenzi, Martin Kowarsch, Luisa Arndt, Lulzim Baumann, Jody Betzien, Lesly Fonkwa, Bettina Huber, Ernesto Mendez, Alexandra Misiou, Cameron Pearce, Paula Radman, Paul Skaloud, J. Marco Zausch

\title{
Fair street space allocation: ethical principles and empirical insights
}

Journal article | Accepted manuscript (Postprint)

This version is available at https://doi.org/10.14279/depositonce-11458

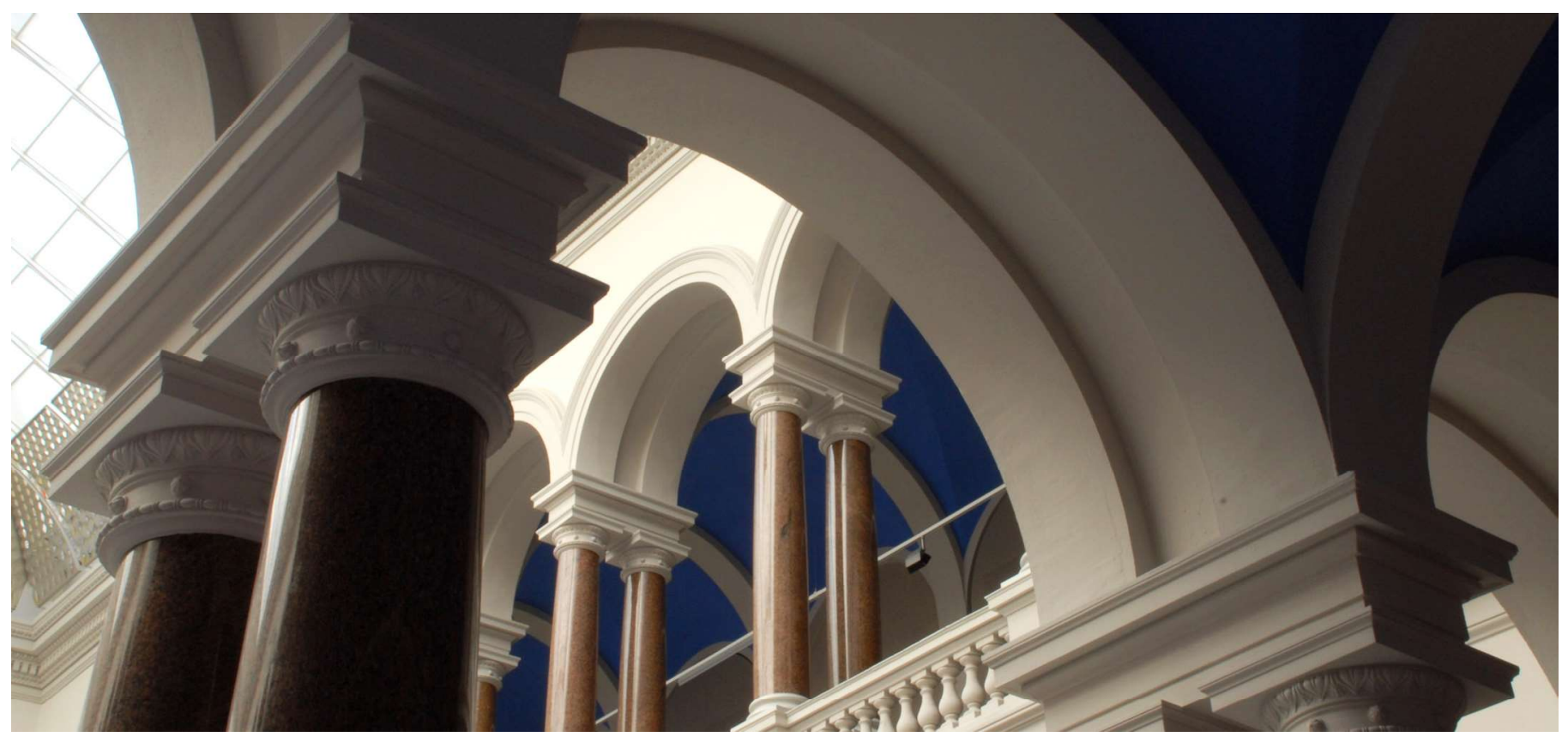

Creutzig, F., Javaid, A., Soomauroo, Z., Lohrey, S., Milojevic-Dupont, N., Ramakrishnan, A., Sethi, M., Liu, L., Niamir, L., Bren d'Amour, C., Weddige, U., Lenzi, D., Kowarsch, M., Arndt, L., Baumann, L., Betzien, J., Fonkwa, L., Huber, B., Mendez, E., ... Zausch, J. M. (2020). Fair street space allocation: ethical principles and empirical insights. Transport Reviews, 40(6), 711-733. https://doi.org/10.1080/01441647.2020.1762795 


\section{principles and empirical insights}

Felix Creutzig ${ }^{a, b}$, Aneeque Javaid ${ }^{b}$, Zakia Soomauroo ${ }^{a, c}$, Steffen Lohrey ${ }^{a}$, Nikola Milojevic-

Dupont $^{a, b}$, Anjali Ramakrishnan ${ }^{a, b}$, Mahendra Sethi ${ }^{a, b}$, Lijing Liu ${ }^{a}$, Leila Niamir ${ }^{b}$, Christopher Bren d'Amour ${ }^{a, b}$, Ulf Weddige ${ }^{b}$, Dominic Lenzi ${ }^{b}$, Martin Kowarsch ${ }^{b}$, Luisa Arndt ${ }^{a}$, Lulzim Baumann ${ }^{a}$, Jody Betzien ${ }^{a}$, Lesly Fonkwa ${ }^{a}$, Bettina Hubera, Ernesto Mendez ${ }^{\mathrm{a}}$, Alexandra Misiou ${ }^{\mathrm{a}}$, Cameron Pearce $^{\mathrm{a}}$, Paula Radman ${ }^{\mathrm{a}}$, Paul Skaloud ${ }^{\mathrm{a}}$ and J. Marco Zausch ${ }^{\mathrm{a}}$

aSustainability Economics of Human Settlements, Technical University Berlin, Berlin, Germany;

bMercatorResearch Institute on Global Commons and Climate Change, Berlin, Germany;

${ }^{\mathrm{C}}$ Reiner Lemoine Institute,Berlin, Germany

Abstract. Urban street space is increasingly contested. However, it is unclear what a fair street space allocation would look like. We develop a framework of ten ethical principles and three normative perspectives on street space - streets for transport, streets for sustainability, and streets as place - and discuss 14 derived street space allocation mechanisms. We contrast these ethically grounded allocation mechanisms with real-world allocation in 18 streets in Berlin. We find that car users, on average, had 3.5 times more space available than non-car users. While some allocation mechanisms are more plausible than others, none is without normative implications. Without exception, all principles suggest that on-street parking for cars is difficult to justify, and that more space should be allocated to cycling. We argue that street space fairness principles should be systematically integrated into urban and transport planning. 


\section{Introduction}

Street spaces shape public life in the city. Streets are multifunctional, used by all, and these uses have been contested throughout urban history. Following the advent of individual motorized vehicles early in the $20^{\text {th }}$ century, transport engineers allocated street space for a singular function: the movement of motorized vehicles, subordinating other uses. The corresponding shift in street space allocation and design has had profound social, environmental and economic impacts, many of which are not immediately apparent (Appendix A). Another transition is now underway driven by a number of factors including, increasing congestion and conflicts over space in inner cities, the rapid ascent of new mobility services, and climate change and sustainability ethics questioning GHG emissions and resource use. In this context, fair street space allocation is a key challenge. Moreover, questions of fairness are salient to users of urban transport systems. Despite this, the question of fair street space allocation is surprisingly little explored in the literature and academic discussions.

Street allocation differs from city to city, from district to district, and from street to street. Cities diverge in their transport patterns and can be sorted into different types, including walking cities, transit cities or auto cities (Barter, 1999). While some cities actively strive for low-carbon transport systems (e.g. Copenhagen, Medellin, or Freiburg (Buehler \& Pucher, 2011; Colville-Andersen, 2018; Creutzig et al., 2012; Fernandez Milan \& Creutzig, 2017)), the predominant model of urban development is still oriented towards the car. Traffic engineers still optimize the allocation of road space towards maximizing traffic flow, and justify such framing with cost-benefit analysis (Currie et al., 2007; Zheng \& Geroliminis, 2013). This in turn codifies a (hidden) political choice prioritizing car mobility over cycling, walking and public transit (Hartman \& Prytherch, 2015; Nello-Deakin, 2019). But cities that discourage human-scale mobility drive social exclusion by penalizing residents without a car (Boyce, 2010). In fact, urban streetscape design translates into access

51 and equity in the city, and is an indicator for quality of life (Dover \& Massengale, 2013). At the 52 local level, communities are increasingly reclaiming the street as a public space. For instance, 53 spearheaded by Jan Gehl and others, Copenhagen street space is a model for human-scale 54 mobility (Gehl, 2013). Other solutions are spreading globally. Inspired by Ciclovia, a weekly event 55 in Bogota, Colombia, there is now a Raahgiri Day every Sunday in Gurgaon and Delhi, India, 56 during which stretches of road are blocked to motorized vehicles and opened to the public. The 57 overall urban mobility narrative also appears to be changing. Emerging concerns about transport 58 emissions, global warming, public health and urban sustainability have reinvigorated public 
discussion about the function and fairness of street space allocation. In this context, it has become increasingly important to systematically study ethical principles of street space allocation.

61 In this paper, we investigate the fairness principles of street allocation. We first outline ten ethical

62 principles, three normative perspectives on the purpose of street space, and develop 14 allocation

63 mechanisms (AM) that we map in relation to the ethical principles. We then compare the fairness

64 principles with current street space allocation, using Berlin as our case study. We uncover a

65 systematic bias in current street space allocation towards private cars, especially space allocation

66 for car parking, which cannot be justified by any of the underlying ethical principles or normative

67 perspectives. We thus call for a reconsideration of street space planning paradigms, designing

68 new ones, that respect ongoing urbanization, the local desire for livable places, and the planetary

69 crisis, and that build on widely accepted ethical principles.

70

$71 \quad$ 2. Methods

72 Our methods comprise a theoretical conceptualization, rooted in ethical theories and normative 73 perspectives, and an empirical analysis (see Figure 1).

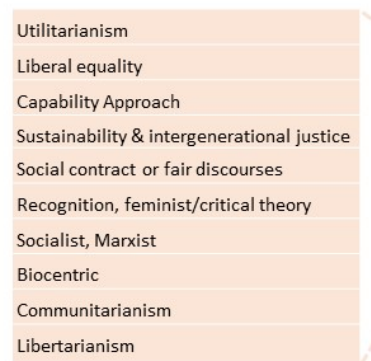

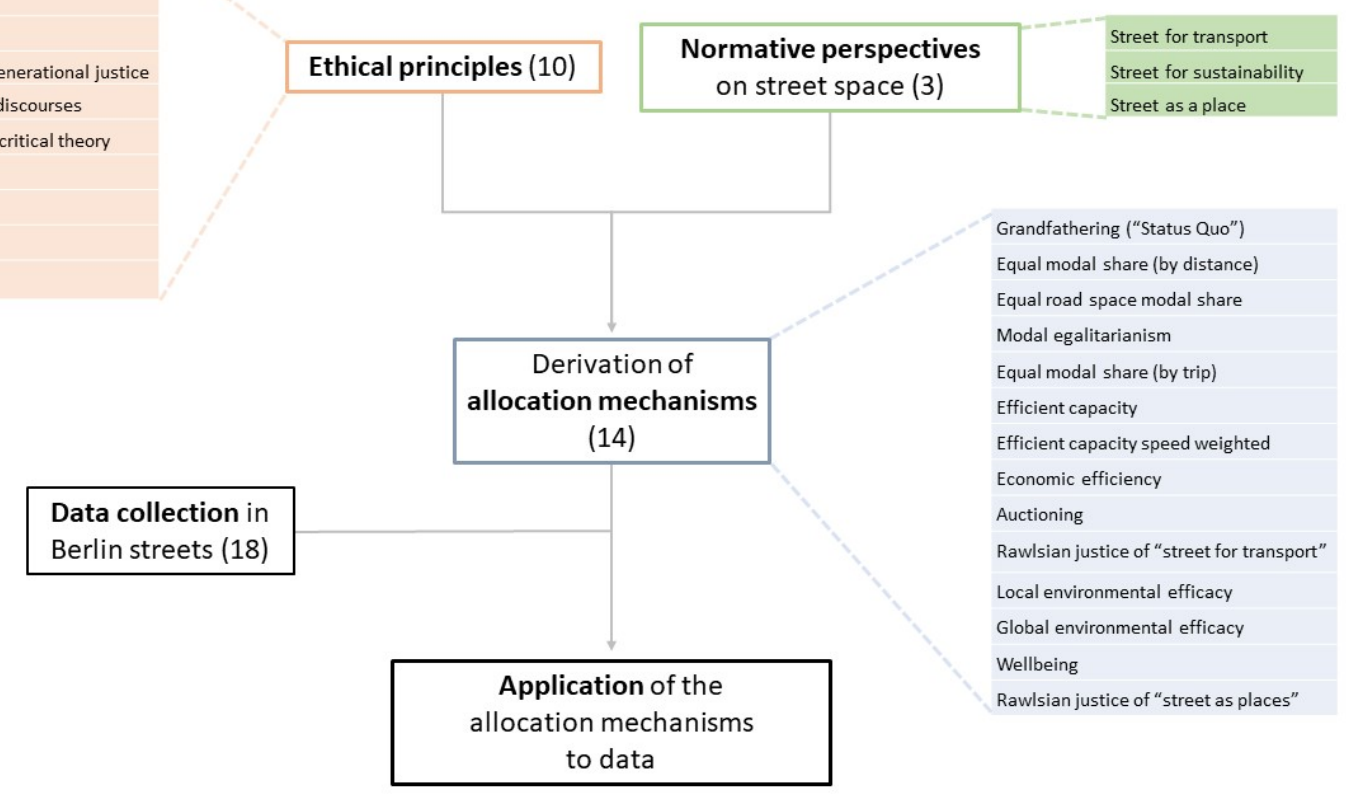

74

Figure 1 | Methodological Flow of the paper. Ethical principles (10) and Normative perspectives on streetscapes (3) are merged in a framework to derive 14 Allocation Mechanisms and corresponding metrices to assess them. Data collected from a primary survey of Berlin streets and secondary data is applied to quantify and analyze the metrices. 
The ethical analysis has two components. We establish our base ethical framework using ten ethical principles (see 2.1) and complement it with three more specific normative perspectives on streetscapes (see 2.2). We devise fourteen allocation mechanisms that in our interpretation reflect

82 both the ethical principles and normative perspectives. As recommendations on desirable street

83 allocation do not solely depend on ethical principles but also upon cities' infrastructure, we 84 propose metrics to quantify current street space.

85 In our case study of Berlin, we quantitatively assess street allocation at the city-level and use in86 depth street-level examples. At the city-level, data for the empirical analysis is gathered from 87 existing literature. This data offers representative statistics of street space allocation. At the street 88 level, additional data was collected in 18 streets of Berlin in order to provide a concrete impression 89 of how allocations materialize in actual human-experienced environments. We then retrieved 90 street level information about space allocation and number of users of each transportation mode.

\subsection{Ethical principles} Our analysis builds on standard ethical principles taken from past and contemporary debates in practical philosophy (Bird, 2019; Kymlicka, 2002; Wolff, 2015). For simplicity, we only focus on the most essential characteristics of the ethical principles and apply them to the basic street space issue (Table 1). We divide these ethical principles across three dimensions: (1) what they regard as key ethical values (e.g. liberties, happiness or well-being or capabilities, fair procedures, or community values); (2) who should be taken into account as moral objects (e.g. contemporary populations only - worldwide or only within a particular community -, or also future generations, or all living beings, as claimed by biocentrism); and (3) the principle/s of distribution used to allocate goods (e.g. equality, overall aggregate wellbeing, sufficiency, or priority for the worst-off). While this does not offer a comprehensive account of the ethical principles, covering the "key distinguishing features" of each of these principles here provides us with the opportunity to open up the debate about street justice towards, making alternative normative viewpoints explicit. 
113 Table 1. Ten Ethical principles, their proponents, and how they relate to street space

114 issues.

\begin{tabular}{|c|c|c|}
\hline Ethical principle & Key Proponents & Core ethical aspects of street space issue \\
\hline Utilitarianism & $\begin{array}{l}\text { Jeremy Bentham } \\
\text { John Stuart Mill } \\
\text { Peter Singer }\end{array}$ & $\begin{array}{l}\text { How can street space allocation serve the goal of maximizing } \\
\text { aggregate happiness? }\end{array}$ \\
\hline Liberal equality & John Rawls & $\begin{array}{l}\text { How does a fair street space allocation ensure equal basic } \\
\text { liberties, and benefit the least well-off? }\end{array}$ \\
\hline $\begin{array}{l}\text { Capability } \\
\text { Approach }\end{array}$ & $\begin{array}{l}\text { Amartya Sen } \\
\text { Martha Nussbaum }\end{array}$ & $\begin{array}{l}\text { How does the street space set-up enable or restrict the } \\
\text { availability of valuable choices, capabilities, and functionings? }\end{array}$ \\
\hline $\begin{array}{l}\text { Sustainability \& } \\
\text { intergenerational } \\
\text { justice }\end{array}$ & $\begin{array}{l}\text { Brian Barry } \\
\text { Eric Neumayer } \\
\text { Derek Parfit }\end{array}$ & $\begin{array}{l}\text { How does urban allocation affect the choices open to future } \\
\text { generations, and the functioning of natural systems? }\end{array}$ \\
\hline Fair discourses & Jürgen Habermas & $\begin{array}{l}\text { To what extent is street space allocation decided by } \\
\text { procedures grounded in the equal moral status of persons? }\end{array}$ \\
\hline $\begin{array}{l}\text { Recognition, } \\
\text { feminist/critical } \\
\text { theory }\end{array}$ & $\begin{array}{l}\text { Gerda R. Wekerle } \\
\text { Clare Cooper Marcus } \\
\text { Anita Sarkissian }\end{array}$ & $\begin{array}{l}\text { How does street space allocation redress pre-existing power, } \\
\text { gender, wealth, and social status inequalities? }\end{array}$ \\
\hline Socialist, Marxist & $\begin{array}{l}\text { Karl Marx } \\
\text { Friedrich Engels } \\
\text { Robert Owen }\end{array}$ & $\begin{array}{l}\text { How does street space allocation help to redress class } \\
\text { imbalances and inequalities? }\end{array}$ \\
\hline $\begin{array}{l}\text { Environmental } \\
\text { values, including } \\
\text { biocentric views }\end{array}$ & $\begin{array}{l}\text { Albert Schweitzer } \\
\text { Paul W. Taylor } \\
\text { Aldo Leopold }\end{array}$ & $\begin{array}{l}\text { How does human use of street space influence non-human } \\
\text { living beings and ecosystems? }\end{array}$ \\
\hline $\begin{array}{l}\text { Communitarianis } \\
\mathrm{m}\end{array}$ & $\begin{array}{l}\text { John Goodwyn Barmby } \\
\text { Michael Walzer } \\
\text { Michael Sandel }\end{array}$ & $\begin{array}{l}\text { How does street allocation affect community life and cultural } \\
\text { values? }\end{array}$ \\
\hline
\end{tabular}




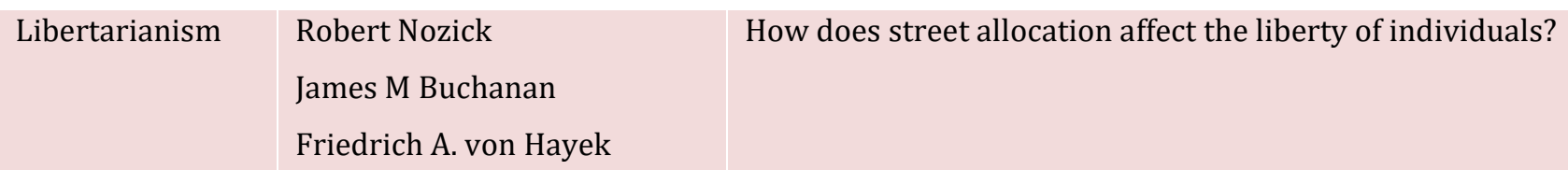

\subsection{Normative perspectives and allocation mechanisms}

To normatively evaluate the allocation of street space, we also specify three prevalent normative perspectives, which imply several of the more fundamental ethical principles: 1) a transport-only perspective (streets for transport), 2) a climate and sustainability perspective (streets for sustainability), and 3) a wellbeing perspective (streets as a place). They serve as organizational principles that guide street allocation. These perspectives are elaborated through core components that link the effects of urban transportation and street space allocation with the corresponding perspective (see appendix for detailed discussion). Streets for transport includes narrow economic/transport engineering utilitarian considerations, whereas broad morally utilitarian perspectives are reflected in streets as a place. Rawlsian deliberations enter both streets for transport (the difference principle within all transport users) and street as a place (the difference principle within all users of streets, even if not for mobility purposes). For details on the normative perspective see Appendix B.

For each perspective, we formulated several plausible operational definitions that we call 'allocation mechanisms' (AMs) - guidance metrics for evaluating fairness of space distribution. AMs specify the normative perspectives, which are in turn motivated by one or more specific ethical principles. Nonetheless, given the inherent vagueness and interpretability of ethical principles, we do not claim that other interpretations are impossible. Our interpretations are merely one plausible way to interpret them. Fig. 2 presents the three organizational principles, their specifications as street space allocation mechanisms (AMs) and their connection with the different ethical principles. 


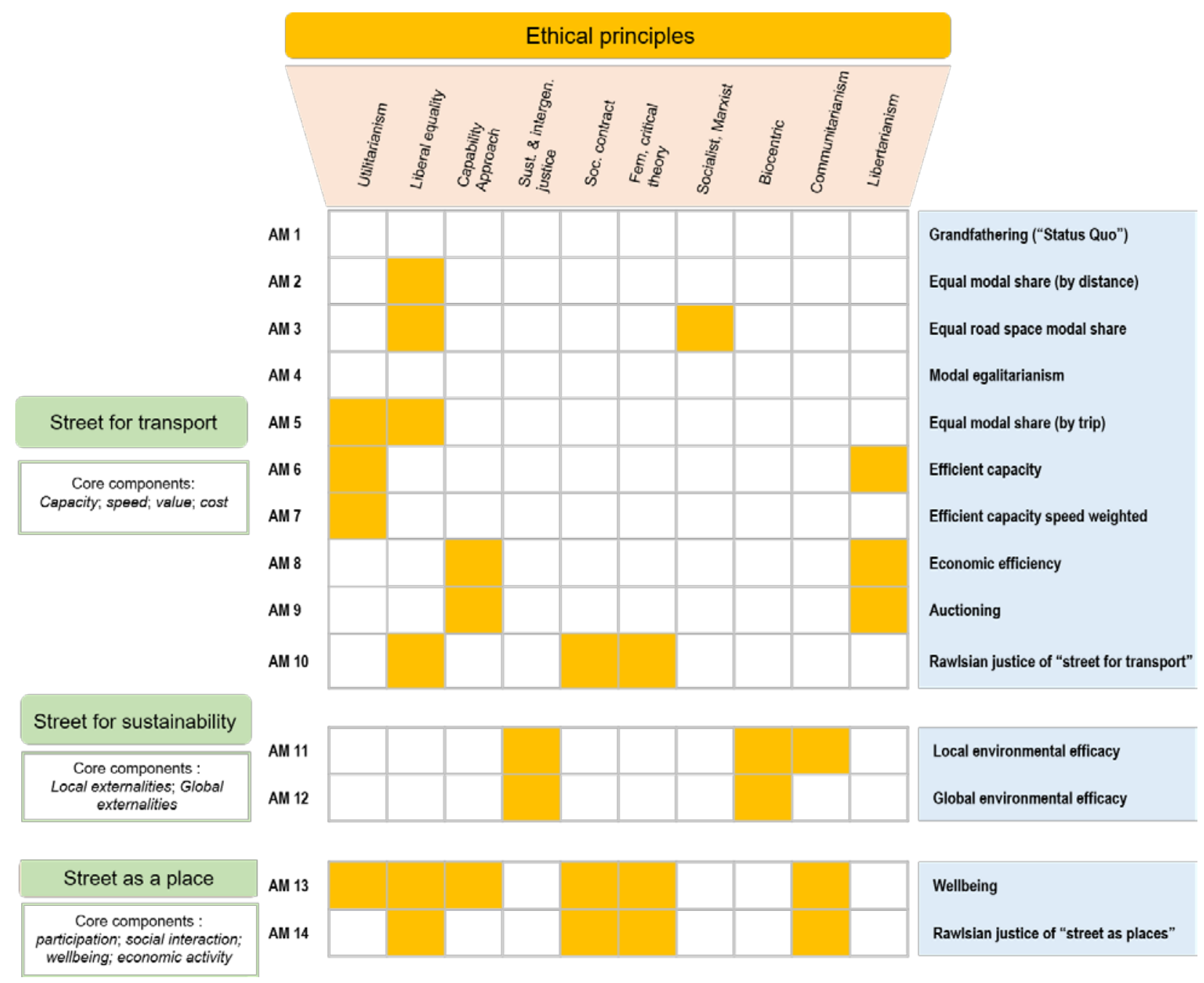

141 Figure 2. Allocation Mechanisms and ethical principles. The grid maps the 14 allocation

142 mechanisms across the ethical principles and normative perspectives. The mechanisms are

143 grouped based on the respective normative perspectives.

145 AM 1 (Grandfathering) represents the status quo and as such is not based on any explicitly 146 considered normative perspective. Rather it reflects the current situation and serves as a baseline 147 for comparison to other scenarios. The majority of the proposed allocation mechanisms (AMs) 148 address the purpose of streets for transport. AMs 2-5 explicitly consider modal share, and are 149 drawn bottom-up from a transport engineering view. They are partially motivated by transport150 utility concerns. AM 2 takes modal share by travel distance as the relevant core element, whereas 151 AM 3 and AM 5 consider road space and modal share by trip number as the relevant metrics 152 respectively, thus giving similar value to each road user. The ethical principle of liberal equality, 153 but also interpretations of utilitarianism and socialism underpin thus street space allocation. AM 
1544 strives for functional clarity by providing equal space to all modes, and serves as an example

155 that can hardly be justified by any ethical principle. AM 6-8 base allocation on efficiency of the 156 mode in terms of carrying capacity or economic value (trip/km), reflecting both utilitarian and 157 capability-based ethics. AM 9 and 10 address the use of the street for transport by allocating 158 space to those who pay most for the change, reflecting the libertarian priority given to individual 159 autonomy, regarding the status quo distribution as presumptively justified. AM 10 explicitly adopts 160 the difference principle of Rawls, and allocates streets to improve mobility of those who are least 161 advantaged.

162 Streets for sustainability is addressed by AMs 11 and 12 that lay out normative considerations for 163 environmental efficacy. At the same time, owing to different scales of their efficacy (11 - local and 16412 - global), they prove useful in meeting transport needs when specified together, and not 165 separately. Local environmental efficacy (AM 11) aims to minimize local air pollution while Global 166 environmental efficacy (AM 12) would aim to minimize the implications for climate change and 167 resource use. The two AMs satisfy principles of sustainability \& intergenerational justice and that 168 of environmental values, including those of biocentrism, ecocentrism, environmental pragmatism, 169 and enlightened anthropocentrism. AM 13 addresses the purpose of streets as a place, 170 emphasizing human needs, capabilities, and wellbeing for all, but also reflecting 171 communitarianism. AM 14. AM14 combines the previous view with that of Rawls, giving 172 additional emphasis to those least advantaged, such as children and the elderly. Berlin's explosive expansion at the turn of the 20th century was fueled by the then new technology of rail-based mass-transit such as tramways. Post-war reconstruction efforts, in contrast, aimed at a transformation towards a car-friendly city, erasing previous urban structures for highway construction in both the East and the West. In the decades after World War II, all strategies were focused on motorized transport (Thomson, 1978). Despite a history of automobility promotion, resulting in nearly $60 \%$ of street space allocated to cars, in contemporary Berlin only $17 \%$ of all trips are made by car (Agentur für clevere Städte, 2014). The city has a very low-rate of motorization by global standards - 342 cars per 1,000 inhabitants, and 0.47 cars per household inside the "S-Bahn Ring" (Jahn \& Krey, 2014). A representative study found that 39\% of Berlin's public-street area is dedicated to driving cars and $19 \%$ to parking them, meaning that more than half $(58 \%)$ of the city's public street space is consumed by the least space-efficient mode of transport, the automobile. $33 \%$ of street space remains for pedestrians, and only $3 \%$ is dedicated 
cycling infrastructure (Agentur für clevere Städte, 2014). In addition, there are 130,000 off-street parking spaces, 50,000 attached to supermarkets or discounters, and 80,000 in parking garages (Reidl, 2019). Yet, even though street space is car centered, cars are not the dominant mode of transport. In the inner city, where the survey presented in this paper was conducted, $35 \%$ of trips are made by walking, $29 \%$ by public transportation, $18 \%$ by cycling and only $17 \%$ by car (Ließke, 2013). The total Berlin modal share of trips, including in the suburbs, breaks down to $26 \%$ by walking, $27 \%$ by public transit, $15 \%$ by cycling, and $34 \%$ by cars (Nobis, 2019). This clearly demonstrates the necessity to distinguish settlement patterns in transportation analyses. Overall, a slight majority of households (51\%) do not own a car (Jahn \& Krey, 2014). And even though Berlin is the city with lowest car ownership in Germany, the existing 1.2 million cars would require a car lane of $7.200 \mathrm{~km}$ length for parking alone (the street network is $5.452 \mathrm{~km} \mathrm{long}$ ) (Reidl, 2019).

In the following, we first provide data on street allocation as collected for the case of Berlin. Second, we compare the observed street space allocation with allocation mechanisms and underlying ethical principles. This allows us to understand the different practical policy implications, which emerge from comparison of ethical principles and allocation mechanisms to observed data.

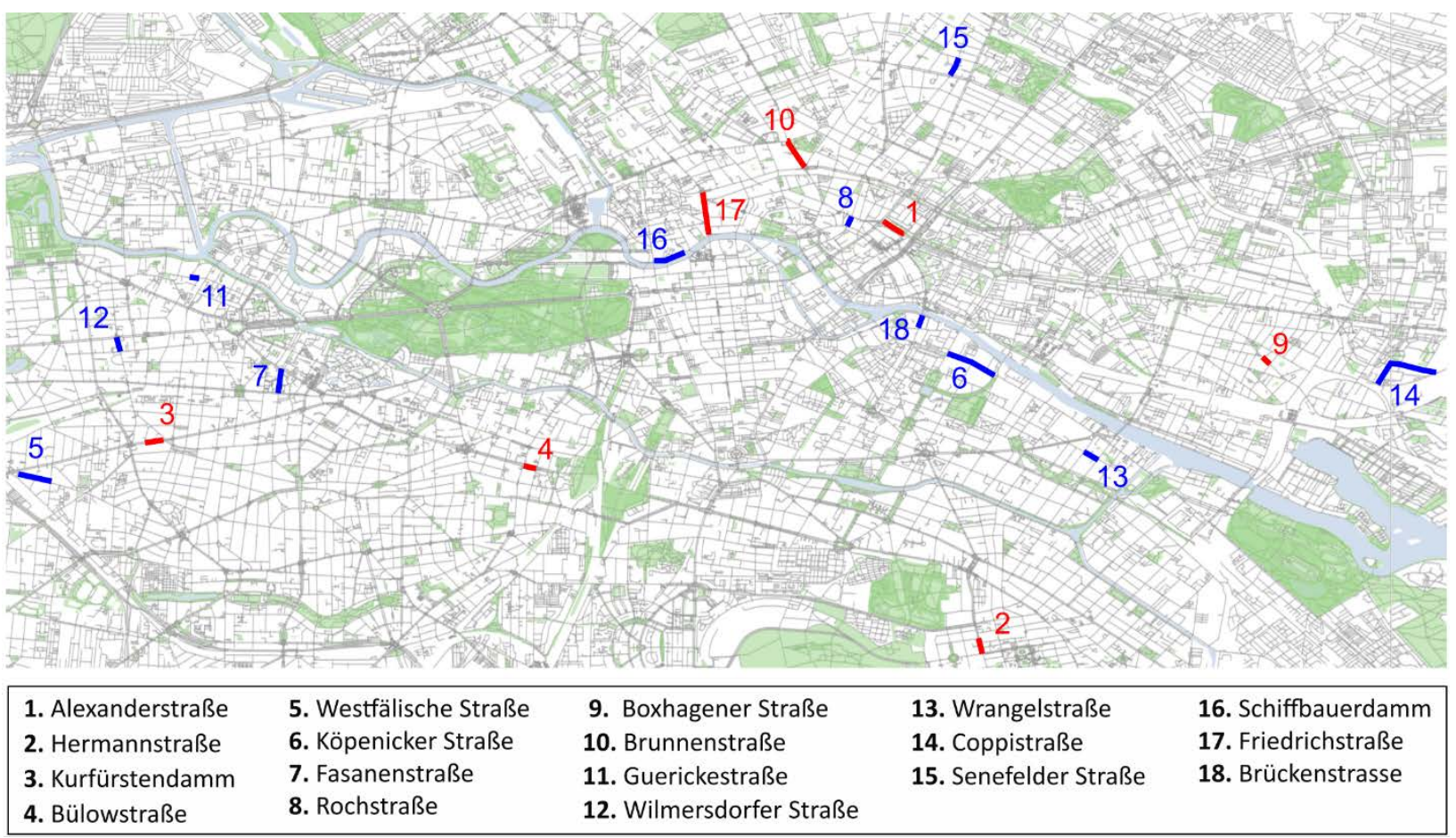


206 Figure 3. Map of Berlin focused on the streets surveyed: 18 Streets of Berlin surveyed to collect data on mode-wise street space and usage, user counts, social constructs (interactions and urban environment) of the streets. Map sourced from OpenStreetMap.

We measured street space allocation and counted user numbers on 18 streets in Berlin (Figure 3 ). These represent a variety of street types, section length averaged 250m (see Appendix for detailed statistics). The surveys took place between November and December 2018, during weekday off-peak hours. Summary statistics and street briefs are provided in Appendix C and D. Across all surveyed street segments, a large proportion of space was found to be dedicated to 215 motorized traffic, confirming the findings of a previous study (Agentur für clevere Städte, 2014).

216 On average, car lanes for driving take up 38\% ( $\min 12 \%$, max 58\%), and if street parking is taken 217 into account, the allocation increases to $60 \%$ (36\% to 83\%). 30\% of the space is designated for 218 pedestrians. Seven streets have dedicated cycling and 5 streets have dedicated space for 219 busses. Averaged across all 14 streets $6 \%$ and $4 \%$ of the total space is dedicated to cycling and busses respectively (for computation of allocation where street space has multiple users see Appendix E). Where dedicated public transportation space exists in a street it typically represents more than $15 \%$ of the space, and up to $31 \%$ on the Friedrichstrasse segment surveyed. Cycling represents on average around $10 \%$ where dedicated space is made available. In only one street, Bülowstraße - a very wide street - all five allocation classes were present. In cases without dedicated bicycle lanes or bus/tram lanes, bikes and buses can use the existing car lanes, but at risk of serious accidents, discomfort and congestion. In the subsequent analysis, we assume that space on shared lanes is shared among respective modes according to the modal share surveyed and apply a space occupation ratio of 12:3:1 (cars: bicycles: public transport). The derivation of this ratio is explained in the appendix.

230 User counts indicate a car user share of around 34\%, 29\% for pedestrians, 18\% for public 231 transport, and 16\% for cyclists. Assuming that each parked car also has a user, results in a user 232 share below 5\% for car parking. Standard deviations across the different streets surveyed are 233 large for all modes (Figure G Appendix). 


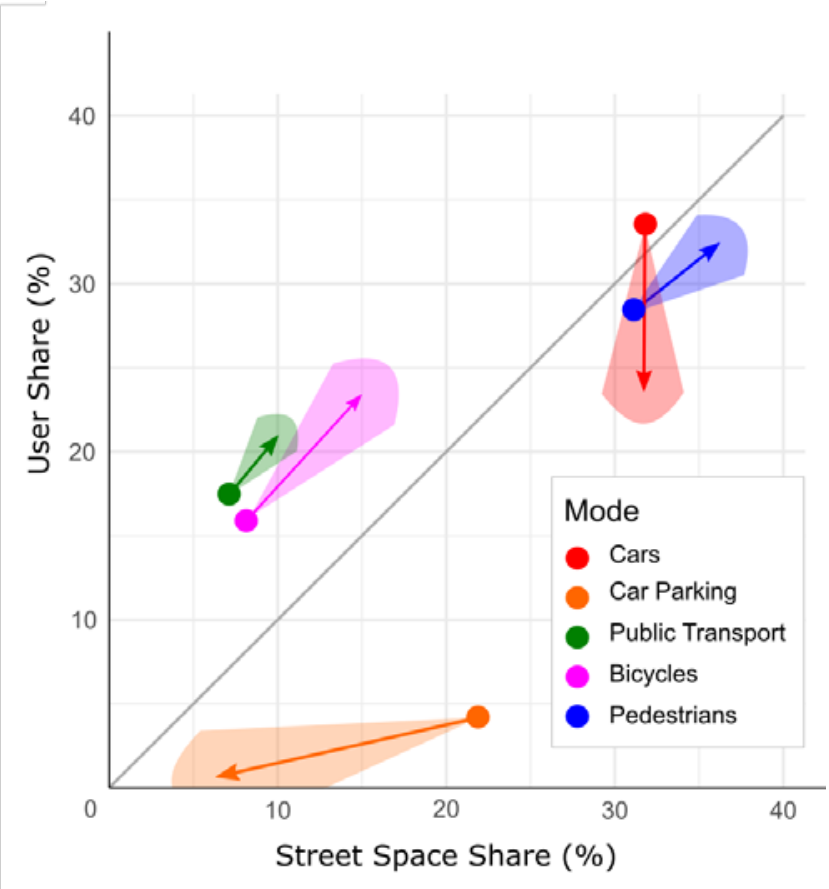

Figure 4. Street space by usage and space allocation for 5 modes presenting mean values of our street sample. Arrows indicate suggested direction of change, resulting from the discussion of ethical principles. Cones represent uncertainty on values. Values are indicative and require street-specific adjustments (Figure $\mathrm{G}$ in Appendix C).

Parked cars occupy most space against usage, whereas cyclists and public transit occupy least space against usage. Modes below the diagonal occupy a disproportionally large amount of space, modes above the diagonal occupy a disproportionally small amount of space.

244 We now investigate the relationship between user share and road space. The diagonal line in 245 Figure 4 provides an indication of how much space each mode occupies relative to its user counts. 246 In relation to ethical principles, this metric is most appropriate for allocation principles 2; 3; 6 and 2477 (see Table 2). In particular, parked cars occupy, on average, 22\% of road space but their 248 assumed user share is at only 4\%. In contrast, user shares for cycling and public transportation 249 modes have been counted at $16 \%$ and $18 \%$ respectively, while the road space share remains 250 below $10 \%$ for both modes. In this assessment road share and user share are fairly similar for 251 driving cars and pedestrians.

252 We also compute allocation ratios of street space use (see Appendix F) confirming a strong bias 253 towards allocating space to individual motorized vehicles and especially parked cars, to the 254 detriment of public transportation and cyclists. Car users, on average, had 1.9 times the space 
255 allocated to cyclists, and more than double (2.2) the space allocated to public transportation 256 users, even when accounting for different space needs on shared lanes. The overall analysis 257 reveals that most of the asymmetric space distribution is due to parked cars.

258

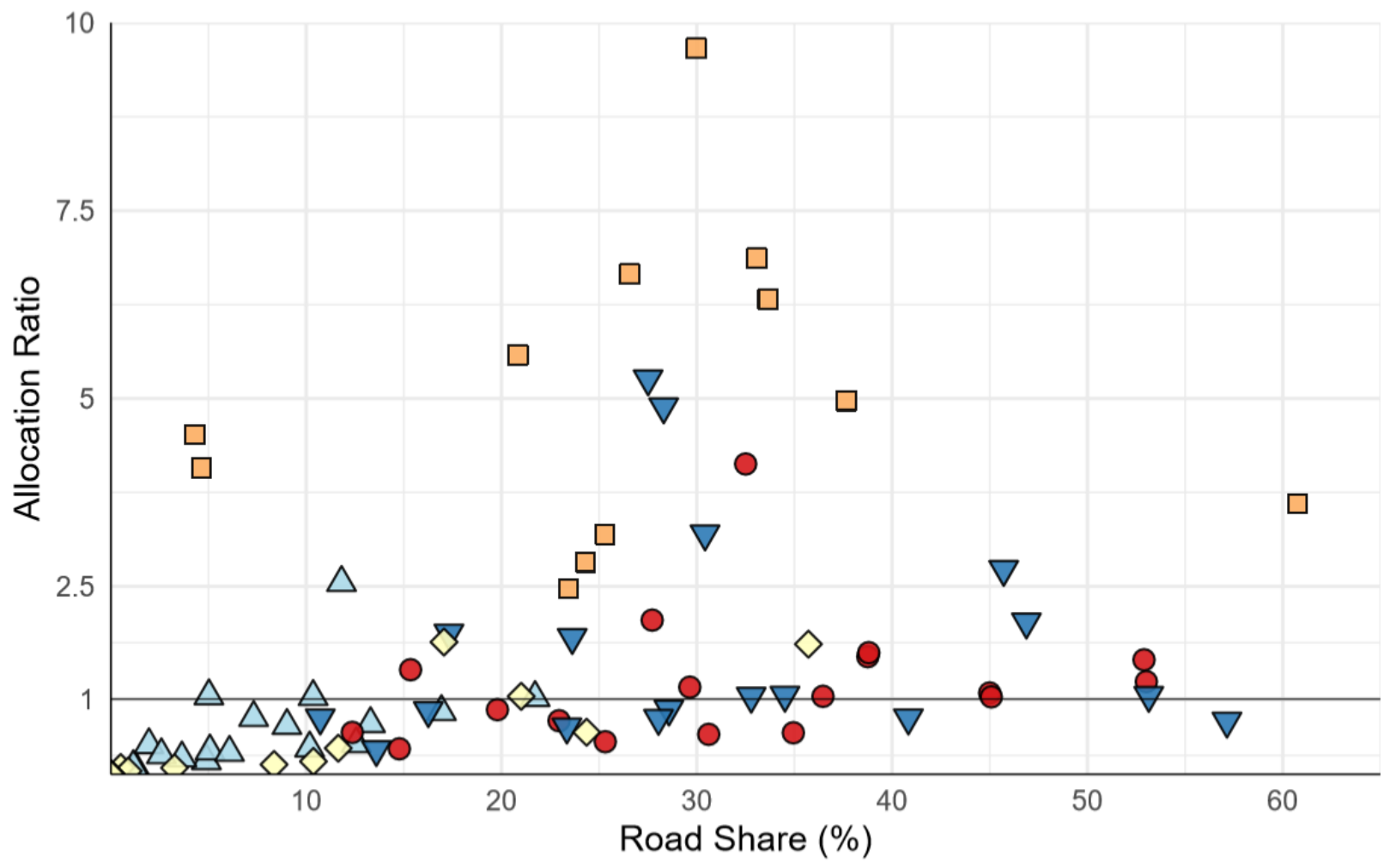

260 Figure 5 | Allocation ratios for surveyed streets. Parking dominates street space use in 16 out of 18 261 cases. In three cases, allocation ration for parking is outside the range depicted here.

Table 2 | Allocation mechanisms for fair street space allocation. Quantitative estimation from our 264 sample of Berlin streets (comparable to other observations, such in (Agentur für clevere Städte, 2014). 265 Derivation of quantitative values (AM 1-7) is explained in the Appendix. Qualitative values (AM 8-14) are 266 provided by expert judgement within the author team.Underlying calculations are explained in Appendix 267 G. 


\begin{tabular}{|c|c|c|c|c|c|c|c|c|}
\hline & \multirow[b]{2}{*}{$\begin{array}{l}\text { Allocation } \\
\text { mechanism }\end{array}$} & \multirow[b]{2}{*}{$\begin{array}{l}\text { Definition of the } \\
\text { mechanism }\end{array}$} & \multicolumn{5}{|c|}{ Street usage distribution (in \%) } & \multirow[b]{2}{*}{ Evaluation } \\
\hline & & & $\begin{array}{c}C \\
a r \\
s\end{array}$ & $\begin{array}{c}\text { Car } \\
\text { Park } \\
\text { ing }\end{array}$ & PT & $\begin{array}{l}\text { Bicycl } \\
\text { es }\end{array}$ & $\begin{array}{l}\text { Pedestr } \\
\text { ians }\end{array}$ & \\
\hline 1 & $\begin{array}{l}\text { Grandfather } \\
\text { ing } \\
\text { ("Status } \\
\text { Quo") }\end{array}$ & $\begin{array}{l}\text { Remain with the } \\
\text { default conditions }\end{array}$ & 32 & 22 & 7 & 8 & 31 & $\begin{array}{l}\text { Politically adequate, but not normatively } \\
\text { Avoid costs of change }\end{array}$ \\
\hline 2 & $\begin{array}{l}\text { Equal } \\
\text { modal } \\
\text { share } \\
\text { (by } \\
\text { distance) }\end{array}$ & $\begin{array}{l}\text { Space allocation as } \\
\text { per modal share } \\
\text { (distance-based) }\end{array}$ & & 33 & 47 & 14 & 6 & $\begin{array}{l}\text { Inadequate by consequence: distributional outcome } \\
\text { does not correspond to the intuitive understanding } \\
\text { of fairness and adequacy }\end{array}$ \\
\hline 3 & $\begin{array}{l}\text { Equal road } \\
\text { space by } \\
\text { modal } \\
\text { share }\end{array}$ & $\begin{array}{l}\text { Same as equal modal } \\
\text { share, but applicable } \\
\text { on road space only }\end{array}$ & 32 & 4 & 17 & 15 & 31 & $\begin{array}{l}\text { Perhaps of interest, if shared mobility is added to } \\
\text { public transit }\end{array}$ \\
\hline 4 & $\begin{array}{l}\text { Modal } \\
\text { egalitarianis } \\
\mathrm{m}\end{array}$ & $\begin{array}{l}\text { Equal space for each } \\
\text { mode }\end{array}$ & & 25 & 25 & 25 & 25 & $\begin{array}{l}\text { Gives ethical value to } \\
\text { modes not people; unjustified by any ethical } \\
\text { principle }\end{array}$ \\
\hline 5 & $\begin{array}{l}\text { Equal } \\
\text { modal } \\
\text { share (by } \\
\text { trip) }\end{array}$ & $\begin{array}{l}\text { Space according to } \\
\text { modal share (number } \\
\text { of trips) }\end{array}$ & 34 & 4 & 18 & 16 & 29 & $\begin{array}{l}\text { Gives the same value to each trip; Perhaps of } \\
\text { interest of shared mobility is added to PT }\end{array}$ \\
\hline 6 & $\begin{array}{l}\text { Efficient } \\
\text { capacity }\end{array}$ & $\begin{array}{l}\text { Maximize through flow: } \\
\text { street space for higher } \\
\text { capacity modes }\end{array}$ & 2 & - & 69 & 12 & 17 & $\begin{array}{l}\text { Efficiency may be a normatively inadequate metric } \\
\text { if outcome metrics are not or only very indirectly } \\
\text { related to wellbeing. }\end{array}$ \\
\hline 7 & $\begin{array}{l}\text { Efficient } \\
\text { capacity } \\
\text { speed } \\
\text { weighted }\end{array}$ & $\begin{array}{l}\text { Maximize through flow } \\
\text { weighted by speed }\end{array}$ & 3 & - & 81 & 13 & 3 & $\begin{array}{l}\text { Efficiency may be a normatively inadequate metric } \\
\text { if outcome metrics are not or only very indirectly } \\
\text { related to wellbeing. }\end{array}$ \\
\hline 8 & $\begin{array}{l}\text { Economic } \\
\text { efficiency }\end{array}$ & $\begin{array}{l}\text { Allocate street space } \\
\text { according to the } \\
\text { economic value (prefer } \\
\text { fastest mode) }\end{array}$ & - & & + & + & - & $\begin{array}{l}\text { Economic outcome normatively problematic, as } \\
\text { many values and wellbeing dimensions are not } \\
\text { reflected. Parking space for delivery and individual } \\
\text { cars should be treated differently. }\end{array}$ \\
\hline 9 & Auctioning & $\begin{array}{l}\text { Allocate street space } \\
\text { on the basis of who } \\
\text { pays for this change }\end{array}$ & $\begin{array}{l}- \\
\text { I } \\
?\end{array}$ & & $?$ & $?$ & $+/ ?$ & Economic outcome \\
\hline
\end{tabular}




\begin{tabular}{|c|c|c|c|c|c|c|c|}
\hline 10 & $\begin{array}{l}\text { Rawlsian } \\
\text { justice } \\
\text { ("streets for } \\
\text { transport") }\end{array}$ & $\begin{array}{l}\text { Improve accessibility } \\
\text { for the least able (kids, } \\
\text { elders, disabled) }\end{array}$ & $?$ & + & $?$ & ++ & $\begin{array}{l}\text { Improves comfort for the least able at additional } \\
\text { environmental cost }\end{array}$ \\
\hline 11 & $\begin{array}{l}\text { Local } \\
\text { environmen } \\
\text { tal efficacy }\end{array}$ & $\begin{array}{l}\text { Minimize local pollution } \\
\text { (PM, NOx, etc.) }\end{array}$ & - & - & + & + & Ignores individual wellbeing \\
\hline 12 & $\begin{array}{l}\text { Global } \\
\text { environmen } \\
\text { tal efficacy }\end{array}$ & $\begin{array}{l}\text { Minimize climate } \\
\text { change and resource } \\
\text { use }\end{array}$ & - & $+1-$ & + & + & Ignores individual wellbeing \\
\hline 13 & Wellbeing & $\begin{array}{l}\text { Enable a good life by } \\
\text { providing services } \\
\text { relevant for wellbeing, } \\
\text { including subsistence, } \\
\text { leisure, participation, } \\
\text { and identity. }\end{array}$ & - & + & + & ++ & $\begin{array}{l}\text { Gives more weight to wider notions of mobility, } \\
\text { accessibility and possible use of street space. } \\
\text { Normatively adequate in so far as it explicitly } \\
\text { considers wellbeing. How to weigh different } \\
\text { objectives is not answered. May require design } \\
\text { solution. }\end{array}$ \\
\hline 14 & $\begin{array}{l}\text { Rawlsian } \\
\text { justice of } \\
\text { "street as } \\
\text { places" }\end{array}$ & $\begin{array}{l}\text { Improve the usage of } \\
\text { streets for activities for } \\
\text { the least able (kids, } \\
\text { elders, disabled) }\end{array}$ & - & $?$ & + & ++ & $\begin{array}{l}\text { Improves comfort for the least able and improves } \\
\text { environment at the cost of efficiency }\end{array}$ \\
\hline
\end{tabular}

\section{Comparing allocation mechanisms}

269 Here we compare both the overall empirical data on space distribution in Berlin's streetscapes

270 and the in-depth street-specific case studies with the 14 AMs. Where applicable, we quantify the

271 recommendations derived from the allocation mechanisms. Furthermore, we outline how the

272 different allocation mechanisms would alter space allocation in Berlin. For this, we take the

273 existing distribution of space as a basis and modify it according to the principles outlined in section

274 3.1. The results described here are summarized in table 2.

276 AM 1 - Grandfathering. With grandfathering, the existing street space distribution ratios would

277 be kept, mostly benefiting motorized individual transport (cars).

278 AM 2 - Equal modal share by distance. Equal modal share allocates all the space across a

279 road section proportional to total trip distance covered per mode (data here from (Agentur für 280 clevere Städte, 2014)). Attributing space according to modal share strongly reduces space for 281 walking and cars (by 25 and 21 percentage points), mostly to the benefit of public transport which 282 would receive the largest share (nearly half of the street), and to a lesser extent to cyclists. The 283 short distances traveled by pedestrians make their share of space drop to a low of $6 \%$-- which 284 is problematic due to the multiple roles attributed to walking areas as outlined in previous sections, 
and the significance of walking in general. The diminishment of space for walking shows that this allocation principle would lead to a drastic reduction in active transport.

AM 3 - Equal modal share on roads. This is similar to allocation AM 2, but excludes the pedestrian mode, and allocates only the non-pedestrian road space among the other modes. Cars occupy the greatest road space (87\%) and contribute to a third of road trips, while half of road trips are made using public transport, which only gets $6 \%$ of the road space. Based on our data for Berlin streets, attributing road space by road modal share does not majorly change the road space allocation for cars (32\%). However, the road space allocation for PT improves (17\%) taking away space from car parking (4\%). This allocation is more evenly distributed as sidewalks are not affected by the mechanism thus maintaining 31\% of the space. Cyclists increase by 2 percentage points compared to the previous principle (AM 2).

AM 4 - Modal egalitarianism. This principle allocates the same space to every mode. With equal weight to each mode, this mechanism assigns ethical value to the modes and not to the people using them or the purpose or benefit gained from the individual modes. This is not obviously justified by any ethical principle. It also ignores mode efficiency. Relative to current street space, the egalitarian mechanism would increase street space for bicycles and public transport that often occupy little or no road space in cities. Given the varying street space share occupied by cars, parked cars and pedestrian pathways, the direction of change is uncertain, but cyclists and public transit would benefit the most.

AM 5 - Equal mode share by trip. This allocation principle would redistribute space according to the representation of each mode in per-trip modal share. Modal share by trip is a metric commonly used in policy-debates. Corresponding to the Berlin street data, we use the share of users per mode to redistribute the space. Cars and Walking take up the largest share with a percentage of $34 \%$ and $29 \%$, respectively. PT and cyclists each have a proportion of around $20 \%$. Space allocated to parked cars reduce drastically (relative to status quo) when applying the allocation mechanisms. The per-trip proportion of bicycle users is greater than the relative space dedicated to bicycle lanes in most streets. For example, in Guerickestraße, space for car driving is only $10 \%$, while parked cars take up $38 \%$ of the road space. In contrast, $36 \%$ of observed traffic in the street is from cyclists, who have no dedicated road space.

AM 6 - Efficient capacity. This allocation mechanism prioritizes space-efficient modes. A larger share of street space should be allocated to modes with high capacity that maximize throughflow. This would highly benefit public transport and to a lesser extent bicycles, while it would drastically cut space allocated to cars. This mechanism is applicable in transportation planning, particularly in bottlenecks. Applying this allocation mechanism to Berlin street space, PT would 
occupy $69 \%$, followed by walking (17\%) and bike (12\%), and cars would only account for $2 \%$ of space. This contrasts with reality, which gives most space for the mode with the lowest capacity. Street space is nearly always predominantly planned for cars, while the same cannot be said for any other mode except walking. Taking a Berlin example, Friedrichstraße is a shopping and tourist area where there is no dedicated bicycle lane but two shared lanes for cars (and underground public transport). Prioritizing space-efficient modes, such as bikes and e-scooters over cars, could alleviate congestion - and also local air pollution - that is caused by the relatively few car users in that street. This AM has considerable justification in general, but lacks consideration of highvalue motorized transport (e.g. fire services). Further consideration of environmental and placevalues are also not reflected (see below).

AM 7 - Efficient capacity, but speed weighted. Street space would be allocated by capacity as in AM 6, but additionally weighted by the average speed of each transport mode. Based on the assumption that higher velocity results in a more efficient movement, compared to the pure capacity as used in AM 6, more street space would be allocated to transport modes with high average speed. Nonetheless, cars would still obtain only $3 \%$ of the street space, while public transit benefits from this allocation mechanism. Pedestrians would lose even more space. This principle inherently discriminates against slower modes, which are enablers of streets becoming vivid spaces of social interaction, public activities and exchange. A purely transport-efficiency focused allocation mechanism would neglect the importance of street services beyond pure movement.

AM 8 - Economic efficiency. Street space is allocated according to the economic value (willingness-to-pay) associated with each $\mathrm{km}$ of a trip (libertarianism). This means mostly that this AM gives preference to the mode of transit which is the fastest. It is not utilitarian, as the failure to consider those who cannot pay implies that overall happiness or wellbeing is not maximized.

343 Typically, mode-wise economic efficiencies vary daily, or hourly. It is therefore hard to provide a 344 clear hierarchy of modes' efficiency ranges. Reallocation based on economic efficiency will see a reduction in space for walking and parked cars. Delivery vans, that presumably have economic value, would require the maintenance of some parking space, for short-term parking to deliver goods (and thus create economic value). Car dominance appears to reflect the prioritization of economic efficiency. Unpriced congestion is typically a sign that urban transport systems are managed inefficiently. In high-density urban settlements even low car usership can result into congestion across all models. In such circumstances, public transit and cycling rather than cars

351 are systemically more efficient. Congestion charges and parking fees are the main instrument to 352 achieve economic efficiency. 
AM 9 - Auctioning. According to this principle, new street space is allocated on the basis of who pays for the change in space (libertarianism), following (Calthrop \& Proost, 2006). In principle, it offers the opportunity to flexibly reallocate space to the highest value. However, according to other ethical principles such as a capability approach, or Rawlsian justice as fairness, street space is public space, and its privatization may not be desirable. The principle could be applied for parking spaces (which are public spaces squatted by car owners). For example, restaurant owners could bid for parking space in front of their dining spaces to expand seating opportunities. Another concern is that such an AM would amplify existing inequities by increasing the opportunity space for the better-off, while excluding the less well-off. As a benchmark of the value of space, an onstreet parking space should cost the same as an off-street garage space. A private garage space currently costs about €30/month in outer districts and up to €200/month in inner districts (search at immoscout.de; July $17^{\text {th }}$, 2019). For comparison, in the extreme case of Manhattan, where real estate costs are on average 17,000 Euros per square meter in 2019, each 17-square-meter individual parking space has a virtual value of 289,000 Euros; free space attribution to cars yield a high monetary cost for society. One might object that free parking is socially inclusive. Yet, in locations were space has the highest value, such as in Berlin within the S-Bahn Ring, there are ample opportunity of mobility without a car; it is a pure luxury good.

AM 10 - Rawlsian justice for 'street for transport'. A Rawlsian perspective (difference principle) on "street for transport" implies that street-space should be allocated to maximize mobility opportunities for vulnerable and disadvantaged groups, which in many cases translates into space for the slowest mode (pedestrians). In terms of current street-space allocation in selected streets in Berlin the Rawlsian perspective is not amenable to ready-made quantifiable indicators. It instead offers general guidelines on where the status-quo falls short. Vulnerable and transport-disadvantaged groups such as children, seniors, and people with disabilities, require slow mobility environments that are safe from motorized intrusion, are highly accessible and have safe public transport. Berlin has mostly generous street space and many pedestrian areas are adequate for slow movement. Among cases investigated, Hermannstraße and Friedrichstraße are exceptions: shopping opportunities in these streets attract pedestrians but also squeeze them into the little available space. In addition, junctions are often unsafe to navigate, and turning cars pose a constant threat.

AM 11 - Local environmental efficacy. Local environmental efficacy prioritizes modes of transport with the lowest local environmental impacts like air-pollution and noise. AM 11 is compatible with both intergenerational equity and environmental values. Non-motorized modes of transport, such as pedestrians and cyclists, would therefore be preferred. However, modal 
shares of street space in Berlin is weighted heavily towards motorized vehicles. Only one out of the seventeen streets observed, Brückenstraße, had a higher percentage of total street space allocated to bicyclists and pedestrians than to cars, car parking spaces, and public transit. While a certain percentage of every street was available to pedestrians, biking infrastructure was found to be severely lacking, with less than half of the streets providing dedicated bicycle lanes. This AM would involve reducing the amount of space provided to motorized vehicles, to instead increase the size of sidewalks and establish of more bicycle lanes. The extent of the reduction of motorized vehicles and reallocation of road space would depend on the specific targets set, for example based on EU or national policy on air pollution or decarbonization. Limits would be imposed to reduce vehicle speeds, in order to decrease noise pollution and increase the safety of road users. One point of uncertainty is that of public transit, as the results do not distinguish between the types of public transit observed, and thus the extent of their environmental damage. AM 12 - global environmental efficacy. Urban transport and space allocation is associated with two global problems: climate change and land-use change (which drives anthropogenic mass extinction). Priority is given to transport modes with the lowest GHG emissions, and to space allocation that constrains urban sprawl. At the vehicle level, smaller energy-efficient vehicles are preferred over larger ones, and electric and other zero-emission vehicles over diesel or gasoline cars. Bicycles, e-scooters and walking are vastly superior to even EVs, reflecting the large GHG emission footprint embedded in the production of batteries and vehicles (Hill et al., 2019). The average GHG emissions for different modes in decreasing order are: cars (100-143 CO2e g/km tank to wheel), scooter/motorbike (77-107), standard diesel bus (75), Electric car (38), Metro (30.5), train (28), tram (23), cycle/on foot (0)(Sims et al., 2014). Thus, the space allocated to cars is reduced, that of PT might shift to tram/metro considering the capacity, while sufficient space is provided to zero-carbon modes like cycle and pedestrians. AM 12, like AM11, is compatible with both intergenerational equity and environmental values.

412 AM 13 - Wellbeing. The use of streets for transport is instrumentally very important for wellbeing.

413 For streets, this includes a) access to health, education, jobs, leisure b) streets as playgrounds c)

414 Vision Zero - i.e. the avoidance of (fatal) accidents, for example by focusing on high safety and 415 introducing strict speed limits d) public space for social bonding and participation e) public space 416 for experimentation (shared spaces) e) livable neighborhoods and f) freedom of movement. The 417 high dimensionality makes this AM less suited to quantitative indicators, we therefore mainly rely 418 on qualitative observations from different streets in Berlin.

419 Our empirical analysis suggests that participation and identity co-align best with the slow modes, 420 and especially walking. One reason is that more pedestrian space encourages social interaction 
421 that underlie a sense of place (Jacobs, 1992). Qualitative observations from our fieldwork in Berlin 422 suggests that the current infrastructure in most streets is not suitable for meaningful interactions. 423 Instead more space for playful interaction is warranted (Stevens, 2007). This AM also implies 424 that current space allocation for car usage, both active car travel and parking is a significant 425 burden, as it neither improves welfare nor capabilities, nor delivers the constituents of human 426 needs. In fact, we find health burdens such as air and noise pollution, stress for both drivers and 427 other transport mode users (especially active transport modes such as bicycles and walking), and 428 economic externalities such as congestion and lower economic opportunities. Given these 429 adverse impacts on improving the constituents of human needs or capabilities, this AM suggests 430 a significant reduction in space allocated for car usage in Berlin. This AM also indicates that 431 cycling and public transit should be prioritized over personal car usage, as both provide more 432 interaction and sense of social identity.

433 AM 14 - Rawlsian justice for "streets as public spaces". The main objective here is to 434 combine the concept of street space as public space (AM13) with the perspective of the most 435 vulnerable. Greater allocation of public spaces increases the ability of the elderly, children and 436 people with disabilities to relax, enjoy, and have meaningful interactions with others. This AM 437 also stresses the need for street-space allocation for economic opportunities, especially for 438 disadvantaged groups who may not be able to afford traditional spaces for their activities. These 439 include hawkers, stalls, street-performers and micro-economic agents. Our qualitative 440 observations suggest that most streets were unsuitable for social interactions of vulnerable 441 groups. Playful interaction for all can be improved by street design. 


$\begin{array}{lr}\text { Normatively } & \text { Normatively } \\ \text { inadequate by } & \text { inadequate by } \\ \text { outcome } & \text { assumption }\end{array}$

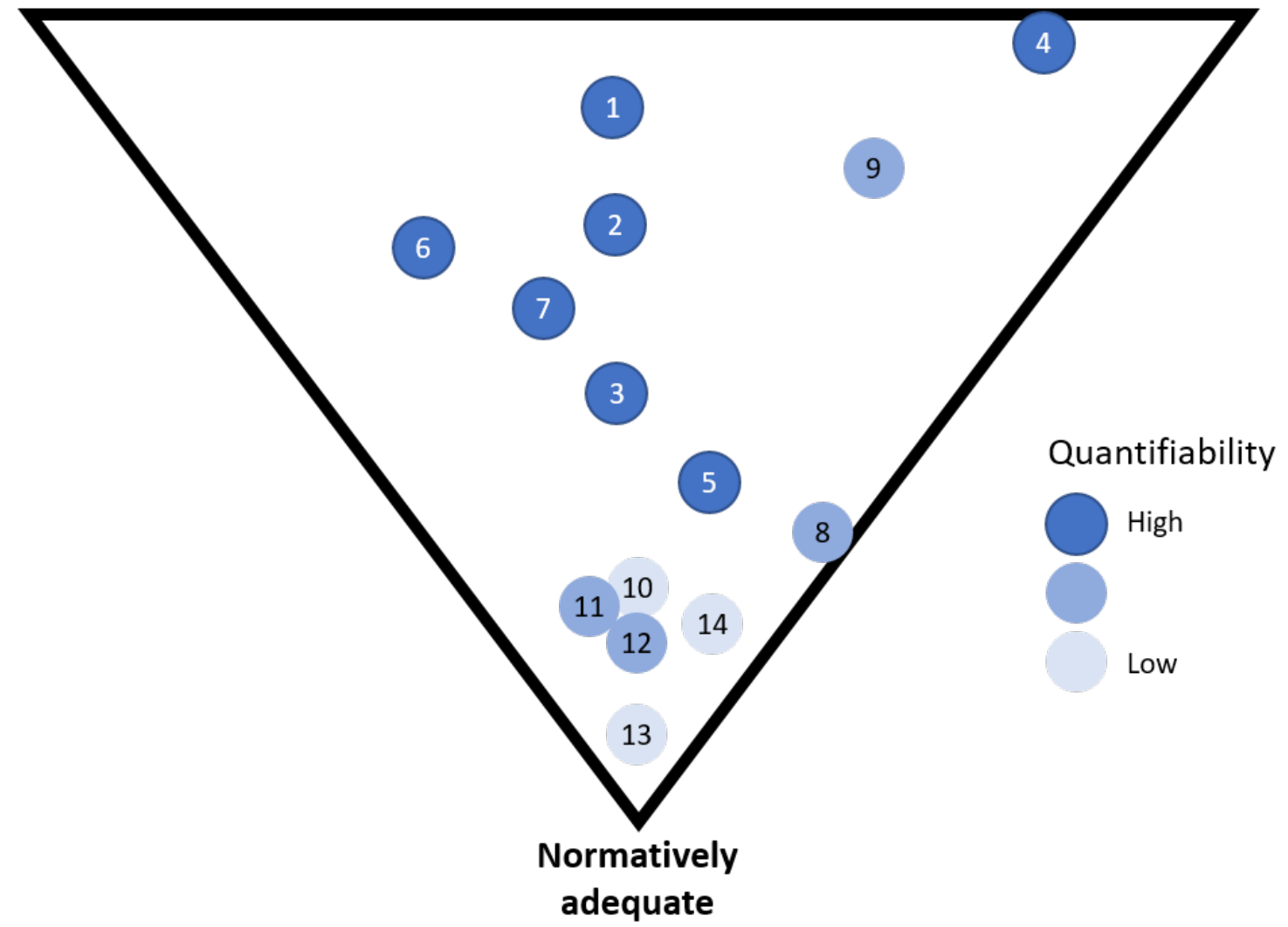

444 Figure 6. Normative adequacy of allocation mechanisms for fair street space distribution.

445 Allocation mechanisms vary widely. Pure transport-based metrics are normatively inadequate,

446 both by assumption and outcome. Economic efficiency is comparatively more adequate.

447 Environmental and human well-being AMs are normatively most adequate but remain limited in 448 scope. A combination of environmental, economic and wellbeing AMs could overcome this 449 concern. Normatively more adequate AMs - that are necessarily high-dimensional and involve 450 issues with open-system boundaries - are less quantifiable.

5. Discussion

452 We discuss first the rationale of the 14 allocation mechanisms, and second the wider justification 453 of trying to allocate street space fairly. 
We introduced 14 allocation mechanisms, derived from three normative perspectives, and evaluated their application for the case of Berlin. In half of all AMs (7 out of 14), we also estimated how each AM would quantitatively re-allocate Berlin street space. In the other 7 we estimated changes qualitatively. Here, we evaluate all 14 AMs relying on three criteria: 1) Is the AM wellgrounded in ethical principles (normatively adequate by assumption); 2) Is the AM intuitively fair by outcome (normatively adequate by outcome)? And 3) How inclusive is the AM with respect to the various dimensions of current and future wellbeing? The results are summarized in Figure 6. Assumptions are understood as ethically inadequate, if the AM is only weakly founded in firm ethical principles. Outcomes are understood as ethically inadequate, if the application of the AM results in outcomes that are counterintuitive to just and balanced street allocation.

The 'street-for-transport' related AMs, especially those that only rely on traffic-related metrics, are normatively inadequate by assumption, but also by outcome, albeit with varying degrees. This is most evident in the case of AM 4 (modal egalitarianism). Modes themselves have no normative value and giving them equal share cannot be grounded in ethics. As absurd as it appears, in other cases, a mode centric approach is taken for granted in transport engineering, where providing spaces for cars (not people) emerges as a questionable objective (Jakle \& Sculle, 2004). AM 4 helps to demonstrate the absurdity of this approach. Similarly, AM 1 (grandfathering) lacks ethical justification. Keeping everything as it is may appeal to status-quo bias, habits and human perception of what is 'normal', working well from the perspective of the political economy, but is neither supported by transport efficiency, nor environmental consideration, nor by human wellbeing. AMs reflecting modal shares (AM 3 and 5) are more interesting as they aim to provide each user equal rights to space, appealing to a basic understanding of fairness. However, these AMs insufficiently reflect the mechanics of public transit. Trams and busses operate under the principle of economics of density and rely on high ridership on minimal space both to be environmentally efficient, and financially viable. Hence, they require barely one third of all street space (AM 3) to operate efficiently (however see the emergent trend of shared mobility discussed below) ${ }^{1}$. The capacity perspective (AM 6 and 7) is even more extreme: because public transit is so capacity-efficient (Figure 2), more than two-thirds of space would be allocated to public transit, compared to a current share of only 3\%. Such a high share for public transit is not needed.

\footnotetext{
${ }^{1}$ These AMs are also subject to an endogeneity problem. If street allocations are redistributed according to observed modal shares, modal shares will change with the modified space. This problem could be solved by an iterative process, assuming that modal shares and street space allocation will converge to a joint stable equilibrium.
} 
However, this evaluation points to the vast potential in making the use of street space more efficient. Together, the purely transport-related AMs are normatively inadequate as they exclude important dimensions of human life, and for not directly targeting individual wellbeing or the public good; however, they provide some interesting food for thought.

The economic AM (AM 8) gives value to street allocation and would translate into making street space allocation more efficient, for example by requiring city-wide pricing of parking, and possibly congestion charging. In principle, it could also include environmental externalities. It is less clear how human well-being could be incorporated, if only because of difficulties of quantification.

493 Clearly, the current practice of free parking could only be maintained if economic evaluations of 494 transport efficiency (and environmental and wellbeing concerns) are continued to be ignored. Auctioning (AM 9) is a specific mechanism that may enable efficient allocation. It is however inconsistent with the notion of transport system as a public service. Auctioning may be applied in a limited context for places that are not required for mobility. For example, on a commercial street, local cafes and shop owners can bid on street-parking opportunities and allocate them flexible for public seating in summer and parking spaces in winter.

The Rawlsian perspective (AM 10) clarifies the importance of catering first for the most disadvantaged in mobility, which may include children, seniors, and disabled people, and thus prioritizes walking. Another implication is that public transit must be designed to be accessible for everyone. However, beyond this, the difference principle provides little guidance on precise

504 allocation of street space.

505 The environmental AMs (AM 11 and 12) are crucial because they open up ethical allocation from purely transport concerns to the wider public good, reflecting local pollution (air quality and noise in AM 11) and planetary stability (AM 12). Yet, their pure application would empty streets from any motorized transport usage. It is hence clear that AM 11 and 12 are most valid in combination with other AMs.

510 The wellbeing allocation (AM 13) is most inclusive but also extremely difficult to quantify (Figure

511 6). It most explicitly combines the function of streets both as infrastructure for transport, and as 512 public space, thus making explicit a core challenge for urban planning (c.f. (von Schönfeld \& 513 Bertolini, 2017)). It is the only one that explicitly considers the wider role of streets as public 514 spaces that broadly serve a diverse suite of constituents of wellbeing, not only transport. That 515 comprises streets as places to play, engage in public activities, and as places worthy of design 516 through participatory and collective action. It is normatively most adequate as it is inclusive in 517 purposes. Italso includes accessibility (the transport dimension), and is supported by most ethical 518 principles (Figure 2). However, its broad perspective, also keeps it away from straight-forward 
transport metrics. Accessibility comprises access to various services: these can be provided by

520 calibrated urban design with short ways, not requiring high street capacity or efficient transport

521 kilometer delivery. Wellbeing is however silent on wider environmental public goods, such as

522 climate change (Among Sustainable Development Goals, wellbeing is represented in SDGs 1-7,

523 while other SDGs explicitly focus on planetary stability, and thus complement the wellbeing

524 dimensions (United Nations, 2020)).

525 Rawlsian allocation considerations (AM 10 and 14) complement the picture and highlight the

526 needs of the most vulnerable, including children, the elderly, and people with disabilities.

527 Our analysis focused mostly on people not freight. Freight relates mostly to the streets for

528 transport perspective and can be relevant for wellbeing, e.g. when delivery goods have important

529 service function, and especially when delivery goods enable access to the otherwise unavailable.

530 Efficient delivery logistics can also reduce the environmental footprint compared to individual

531 shopping. However, in practice free delivery services increase demand for goods that otherwise

532 would not be purchased - scale effects counter any marginal benefit, adding to total

533 environmental burden and increasing congestion. In Berlin, delivery trucks often double park, thus

534 creating both congestion and unsafe situations. This is especially true for cyclists, who may be

535 forced to transgress into oncoming traffic. AM 8 - the application of economic instruments for

536 prioritizing the more important delivery - may provide some guidance for freight transport. A

537 wellbeing perspective, favoring substantial street space for the slow modes and for play, may

538 require a shift from 4-wheeled delivery trucks to 2-wheeled delivery services.

539 Together, our analysis of allocation mechanisms demonstrates that there is no single dominant

540 normative perspective and resulting allocation mechanism to deliver fair street space allocation.

541 The wellbeing AM 13 is most comprehensive and inclusive, but needs to be complemented by

542 the environmental dimensions of $A M 11$ and 12 that are not always direct constituents of

543 wellbeing. The economic allocation (AM 8) alone is insufficient but it can be very helpful in

544 operationalizing the more overarching AMs 11-13. Nonetheless, operationalization should not be

545 traded with inclusiveness. For example, playful street design, participatory design processes, and

546 other dimensions that are hard to operationalize, should remain part and parcel of ethical

547 allocation of street space.

548 The arrows in Figure 4 summarize a semi-quantitative and tentative interpretation of our

549 discussion. The wellbeing perspective argues for more space for pedestrians, more precisely for

550 streets as a place to be, e.g. for kids and seniors, hence the increased space for pedestrians. The

551 increase is only moderate as Berlin already provides decent space in many instances. Public

552 transit gains little road space - in those instances where busses are stuck in congestion. The high 
553 road capacity of public transit translates into few additional space requirement. Cycling gets

554 additional space, and associated higher modal share, reflecting the need for safety, the

555 environmental benefits, and the high wellbeing associated with cycling. Road space for parking

556 cars is reduced dramatically, reflecting its inefficient and unjust current allocation. In contrast,

557 road space for moving cars is kept constant. The spatial reallocation to other modes imply reduced

558 modal share and less congestion.

559

560

5.2. Is fair street space allocation a good question anyway?

562 space allocation (Nello-Deakin, 2019). First, he charges that street space allocation based on

563 observed modal share contrasts with intuitions about fairness, especially as the persistent

564 outcome is the reduction of pedestrian share. Our analysis agrees with this concern. That is why

565 an allocation mechanism that starts with a wider wellbeing perspective, and that prioritizes the

566 condition of the slowest (based on Rawls' difference principle, or the Capabilities approach) is

567 better justified. It also implies that allocation is often place-specific and not subject to any over-

568 simplistic rule of thumb. Second, Nello-Deakin argues that different modes have fundamentally

569 different characteristics. For example, cars require much more space than bicycles, mostly

570 because they are faster. However, we argue that any allocation should start with people, not with

571 modes, and that space allocation based on the needs of specific nodes is hard to justify from any

572 human-centric fairness perspective. Third, he puts forward that streets are not only mobility

573 spaces but also places. Again, we agree and concur by emphasizing the importance of giving

574 high emphasis to a broader wellbeing perspective, such as presented by $\mathrm{AM} 13$, in guiding the

575 allocation of space.

576 A last concern is that we focus our analysis on outcome metrics not on fair procedure (ethical

577 principle based on social contract and fair discourse). This concern is valid: our evaluation focuses

578 on (quantitative) outcome metrics. We suggest however, that a well-being focus that is place-

579 specific and adaptive, is well suited to thrive on procedures that are inclusive to all (local)

580 stakeholders. However the implications are not straight-forward: whereas everyone enjoys

581 walkable or even playful streets, many also want to preserve their (free) parking space in front of

582 their apartment. This indicates a particular type of urban common problem that requires more 583 analysis. 


\section{Conclusion}

585 This is the first paper to discuss justice and ethics of street space distribution, identifying three normative perspectives, breaking them down to 14 allocation mechanisms, and applying them to a selection of 18 street case studies in Berlin. It bridges the gaps between the literature on street space justice (Prytherch, 2018), pragmatic urban transport policy (Bongardt et al., 2013) and realworld measurement. The shortness of the paper format neither allows us to explore all ethical positions and allocation mechanisms in detail, nor does it give justice to all social, environmental, and economic considerations addressed in the vast literature relevant to our topic. But by bringing 592 together ethical philosophy with urban transport design it elucidates a conclusion of high 593 importance: current street space allocation contradicts all considered allocation mechanisms. As 594 the status quo distribution of street space becomes more contested, ethical considerations are of 595 increasing importance in justifying design choices.

596 Our study highlights the difficulty in applying even the simplified ethical principles for ensuring fair 597 street space allocation, and that given practical concerns it is desirable to combine them together 598 in pragmatic manner. Human wellbeing considerations are most inclusive but are often ignored in 599 mechanistic transport planning schemes. Moreover, environmental considerations enter the 600 wellbeing calculus only indirectly; and operationalization remains challenging. Hence, we argue 601 for inclusion of environmental allocation mechanisms and instrumental use of economic efficiency 602 within human wellbeing grounded allocation, while the latter remains dominant, especially in 603 decisions on place-based street design.

6047 out of 14 investigated allocation mechanisms provide quantitative predictions. While the others 605 remain qualitative, there is potential to quantify these too. The predictions of each allocation 606 mechanism vary widely but the trend across all 14 is unambiguous: There is a huge mismatch 607 between current and recommended street space allocation. Specifically, all AMs reveal that cars 608 are provided too much space, whereas bicycles require more space. We found that car users, on 609 average, had 3.5 times more space available than non-car users. However, if only space for 610 moving cars is considered, the difference in space per use is reduced to 1.6 times more space 611 for car drivers over non-car drivers. This calculation demonstrates that most of the asymmetric 612 spaced distribution is due to parked cars rather than driving cars.

613 One shortcoming in our analysis is that the quantitative measurements compare modal shares 614 with modal street allocations, resulting in overly simplistic assumptions. Such an approach could 615 simply reify existing patterns, which reflect the historic results of induced demand. However, even 616 though induced demand is certainly prevalent in real street use, our quantitative analysis 
617 nonetheless suggests a considerable mismatch between road usage and allocation. Hence, our 618 numbers serve as a conservative benchmark. Dynamic and spatially explicit models could take 619 the next step and numerically explore stable equilibrium under a spectrum of different normative 620 perspectives and allocation mechanisms.

621 These results have clear implications for policy and re-assigning street space: Allocating on-street 622 car parking to bicycle lanes and bike and e-scooter parking will be justified from all ethical 623 viewpoints. Our framework provides guidance on the direction, but not magnitude of change. A 624 comparative look, comparing Berlin to Amsterdam, suggests that bicycle lanes should occupy $7 \%$ 625 of street space (c.f. (Nello-Deakin, 2019)). A focus on re-allocating street space should be where 626 pedestrians or cyclists encounters congestion or safety challenges. These are clear indications 627 of insufficient space. Sometimes, especially in smaller streets, an improvement might be achieved 628 by design, not by re-allocation. For example, streets could be redesigned as shared spaces that 629 allow participation by all modes of transport, but that clearly signal, and mandate by design, slow 630 speeds.

631 The most contentious part is the reduction of on-street parking, opposed by highly localized 632 households with car ownership. They might argue: Car users require space for their cars so they 633 can also use it in its active state for driving. There are two layers of considerations here. First, 634 many houses have in-house parking; and there are 130.000 additional off-street parking places 635 in Berlin. Second, and more profoundly, with the onset of shared mobility, the private car passively 636 squatting public spaces for free is not required anymore. High quality mobility services can be 637 delivered by shared bicycles, e-scooters, free-floating car fleets, and ride-pooling, all of which are 638 already on Berlin roads. In fact, with more space available, shared mobility will be able to supplant 639 rather than complement environmentally harmful modes, and thus achieve the sustainability 640 benefits it promises (Creutzig et al., 2019). However, it will require stringent public policies to 641 achieve this goal.

642 Applying fairness principles to street space allocation appears to be revolutionary. The application 643 of fairness principles involves a significant transformation of traditional streetscape allocations 644 that have largely gone unchallenged since the early twentieth century invention of the motorcar. 645 The application of equity and efficiency principles related to mode share would prioritize slow 646 pedestrians and semi-fast cyclists, but cut space allocated to cars. This contradicts the inherent 647 logic of the 'system of automobility' (Urry, 2004), opposes law that subsidizes car driving (Shill, 648 2019), and counteracts existing behavioral biases and habits (Mattauch et al., 2015). Fighting 649 these path dependencies is challenging, but with increasing awareness of streets as contested 
space it also emerges as a priority for decision makers. We wish mayors and administrations of cities the political navigation skills and a mindset grounded in fairness to succeed in these tasks.

\section{References}

Agentur für clevere Städte. (2014). Wem gehört die Stadt? Der Flächen-Gerechtigkeits-Report. Mobilität und Flächengerechtigkeit. Eine Vermessung Berliner Straßen.

Barter, P. (1999). An international comparative perspective on urban transport and urban form in Pacific Asia: The challenge of rapid motorisation in dense cities [PhD Thesis]. Murdoch University.

Bird, C. (2019). An Introduction to Political Philosophy. 2nd edition. Cambridge University Press.

Bongardt, D., Creutzig, F., Hüging, H., Sakamoto, K., Bakker, S., Gota, S., \& Böhler-Baedeker, S. (2013). Low-carbon land transport: Policy handbook. Routledge.

Boyce, C. (2010). Walkability, Social Inclusion and Social Isolation and Street Redesign. BUILT ENVIRONMENT -LONDON- KOGAN PAGE-, 4, 461. edsbl.

Buehler, R., \& Pucher, J. (2011). Sustainable Transport in Freiburg: Lessons from Germany's Environmental Capital. International Journal of Sustainable Transportation, 5(1), 43-70. https://doi.org/10.1080/15568311003650531

Colville-Andersen, M. (2018). Copenhagenize: The definitive guide to global bicycle urbanism. Island Press.

Creutzig, F., Franzen, M., Moeckel, R., Heinrichs, D., Nagel, K., Nieland, S., \& Weisz, H. (2019). Leveraging Digitalization for Sustainability in Urban Transport. Global Sustainability.

Creutzig, F., Mühlhoff, R., \& Römer, J. (2012). Decarbonizing urban transport in European cities: Four cases show possibly high co-benefits. Environmental Research Letters, 7(4), 044042. https://doi.org/10.1088/1748-9326/7/4/044042 
675 Currie, G., Sarvi, M., \& Young, B. (2007). A new approach to evaluating on-road public transport priority projects: Balancing the demand for limited road-space. Transportation, 34(4), 413-428.

678 Dover, V., \& Massengale, J. (2013). Street design: The secret to great cities and towns. John $679 \quad$ Wiley \& Sons.

680 Fernandez Milan, B., \& Creutzig, F. (2017). Lifting peripheral fortunes: Upgrading transit 681 improves spatial, income and gender equity in Medellin. Cities, 70, 122-134.

682 Gehl, J. (2013). Cities for people. Island press.

683 Hartman, L. M., \& Prytherch, D. (2015). Streets to live in: Justice, space, and sharing the road. $684 \quad$ Environmental Ethics, 37(1), 21-44.

685 Hill, G., Heidrich, O., Creutzig, F., \& Blythe, P. (2019). The role of electric vehicles in near-term mitigation pathways and achieving the UK's carbon budget. Applied Energy, 251, 113111.

Jacobs, J. (1992). The death and life of great American cities. 1961. New York: Vintage.

Jahn, H., \& Krey, J. (2014). Berliner Verkehr in Zahlen 2013. Senatsverwaltung für Stadtentwicklung und Umwelt. www.stadtentwicklung.berlin.de

691 Jakle, J. A., \& Sculle, K. A. (2004). Lots of parking: Land use in a car culture. University of Virginia Press.

693 Kymlicka, W. (2002). Contemporary Political Philosophy: An Introduction. Oxford University 694 Press.

695 Ließke, F. (2013). Mobilitätssteckbrief für Berlin. Technische Universität Dresden.

696 Mattauch, L., Ridgway, M., \& Creutzig, F. (2015). Happy or liberal? Making sense of behavior in 697 transport policy design. Transportation Research Part D: Transport and Environment, $698 \quad$ Forthcoming. 
699

700

701

702

703

704

705

706

707

708

709

710

711

712

713

714

715

716

717

718

719

720

721

722

723

Nello-Deakin, S. (2019). Is there such a thing as a 'fair'distribution of road space? Journal of Urban Design, 1-17.

Nobis, C. (2019). Mobilität in Deutschland-MiD Analysen zum Radverkehr und Fußverkehr (im Auftrag des BMVI). infas, DLT, IVT, infas 360. http://www.mobilitaet-in-deutschland.de

Prytherch, D. (2018). Rethinking the Street as Space of Mobility, Rights, and (In)Justice (pp. 13-32). https://doi.org/10.1007/978-3-319-75705-6_2

Regulating on-street parking. (2006). Regional Science and Urban Economics, 36(1), 29-48. https://doi.org/10.1016/j.regsciurbeco.2005.04.002

Reidl, A. (2019, June 3). Verkehrswende: Von den Dänen lernen. Die Zeit. https://www.zeit.de/mobilitaet/2019-05/verkehrswende-mobilitaet-fahrradstadt-berlinradwege-verkehrsplanung

Shill, G. H. (2019). Should Law Subsidize Driving? (SSRN Scholarly Paper ID 3345366). Social Science Research Network. https://papers.ssrn.com/abstract=3345366

Sims, R., Schaeffer, R., Creutzig, F., Cruz-Núñez, X., D’Agosto, M., D Dimitriu, M. F., \& Tiwar, G. (2014). Transport; Chapter 8. O. Edenhofer, R. Pichs-Madruga, Y. Sokona, E. Farahani, S. Kadner, K. Seyboth, JM (Eds.), Climate Change.

Stevens, Q. (2007). The ludic city: Exploring the potential of public spaces. Routledge. Thomson, J. M. (1978). Great cities and their traffic.

United Nations. (2020). About the Sustainable Development Goals. United Nations Sustainable Development. https://www.un.org/sustainabledevelopment/sustainable-developmentgoals/

Urry, J. (2004). The ‘system'of automobility. Theory, Culture \& Society, 21(4-5), 25-39.

von Schönfeld, K. C., \& Bertolini, L. (2017). Urban streets: Epitomes of planning challenges and opportunities at the interface of public space and mobility. Cities, 68, 48-55. https://doi.org/10.1016/j.cities.2017.04.012 
724 Wolff, J. (2015). An Introduction to Political Philosophy. 3rd edition. Oxford University Press.

725 Zheng, N., \& Geroliminis, N. (2013). On the distribution of urban road space for multimodal 726 congested networks. Procedia-Social and Behavioral Sciences, 80, 119-138. 